\title{
Multi-impact evaluation of new medium and large hydropower plants in Portugal centre region
}

\author{
Aníbal T. de Almeida ${ }^{\mathrm{a}, *}$, Pedro S. Moura ${ }^{\mathrm{a}}$, Alféu S. Marques ${ }^{\mathrm{b}}$, \\ José L. de Almeida ${ }^{\mathrm{b}}$ \\ a ISR_Department of Electrical and Computer Engineering, University of Coimbra, Pólo II 3030, \\ Coimbra, Portugal \\ b Department of Civil Engineering, University of Coimbra, Pólo II, 3030, Coimbra, Portugal
}

Received 19 January 2004; accepted 19 January 2004

\begin{abstract}
Traditionally, the decision criteria when analyzing hydropower plants projects, has been based mostly on technical and economical analyses focused on the electric production aspects. Nowadays a broader approach is necessary, which takes into consideration multiple impacts such as:
\end{abstract}

- Energy impacts;

- Water resources impacts;

- Social-economics development impacts;

- Agricultural sector impacts;

- Environmental impacts.

In order to establish a ranking of the 14 new medium and large (power above 10 MW) hydropower plants identified in the Centre Region of Portugal, a multi-disciplinary team of Coimbra University carried out a study about the impacts associated to each of the hydropower plants. The analysis considered the different aspects associated to the multifunctional character of the hydropower plants. The overall ranking of the hydropower plants was achieved using a methodology that integrates the different aspects using a weighing function [2].

(C) 2004 Elsevier Ltd. All rights reserved.

\footnotetext{
${ }^{*}$ Corresponding author. Tel.: +351-239-796-218; fax: +351-239-406-672.

E-mail address: aalmeida@isr.uc.pt (A.T. de Almeida).
} 
Keywords: Hydro-electricity; Hydropower; Multi-objective evaluation; Environmental impacts; Water resources; Regional development; Emissions reduction; Intermittent power sources integration; Reserve capacity potential; Load following

\section{Contents}

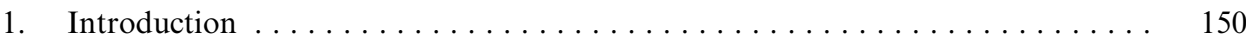

2. Hydropower resources in Centre Region $\ldots \ldots \ldots \ldots \ldots \ldots \ldots \ldots \ldots \ldots$

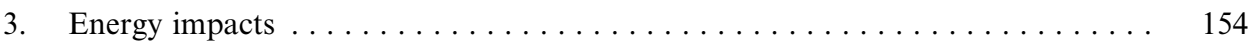

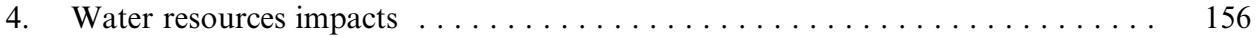

5. Social-economics development impacts $\ldots \ldots \ldots \ldots \ldots \ldots \ldots \ldots \ldots \ldots$

6. Animal and plant life environmental impacts . . . . . . . . . . . . . 159

7. Improvement of forest fire combat capabilities $\ldots \ldots \ldots \ldots \ldots \ldots \ldots \ldots$

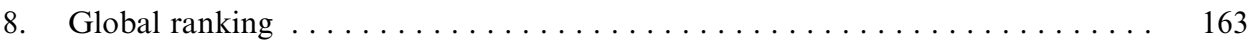

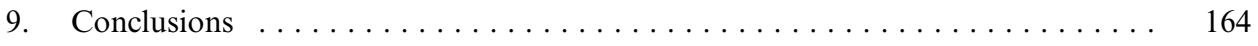

\section{Introduction}

The European Commission has approved general orientations determining that $12 \%$ of the energy production in 2010 should be satisfied by renewable resources (double of the 1990 value). Presently, the Portuguese energy consumption depends on $85 \%$ of imported fossil fuels. The contribution of the renewable energies is based mainly on the electrical power generation. In this sector, hydropower plants produce about $1 / 3$ of the total consumed electricity [5].

To satisfy the European Commission Renewable Electricity Directive (2001/77/ EC), Portugal must attain a 39\% renewable electricity production in 2010. A substantial increase of the hydropower production will be necessary. This Directive encourages a larger promotion of the renewable energies in Portugal, such as hydropower, wind energy, biomass and solar energy.

The Portuguese electricity consumption growth in the last decade was 5-6\% per year. Therefore, the short term programmed projects, including the construction of two new hydropower plants (360 MW) and refurbishment of two existing hydropower plants will not be enough [14]. A significant part of the remaining national hydropower potential must be used. In the utilization of the national hydropower potential, Portugal has a modest position compared with other countries, with only $58 \%$ of the resources used in terms of electricity generation [16]. However, in terms of water storage capabilities, only $40 \%$ of the resources are used (Fig. 1). 


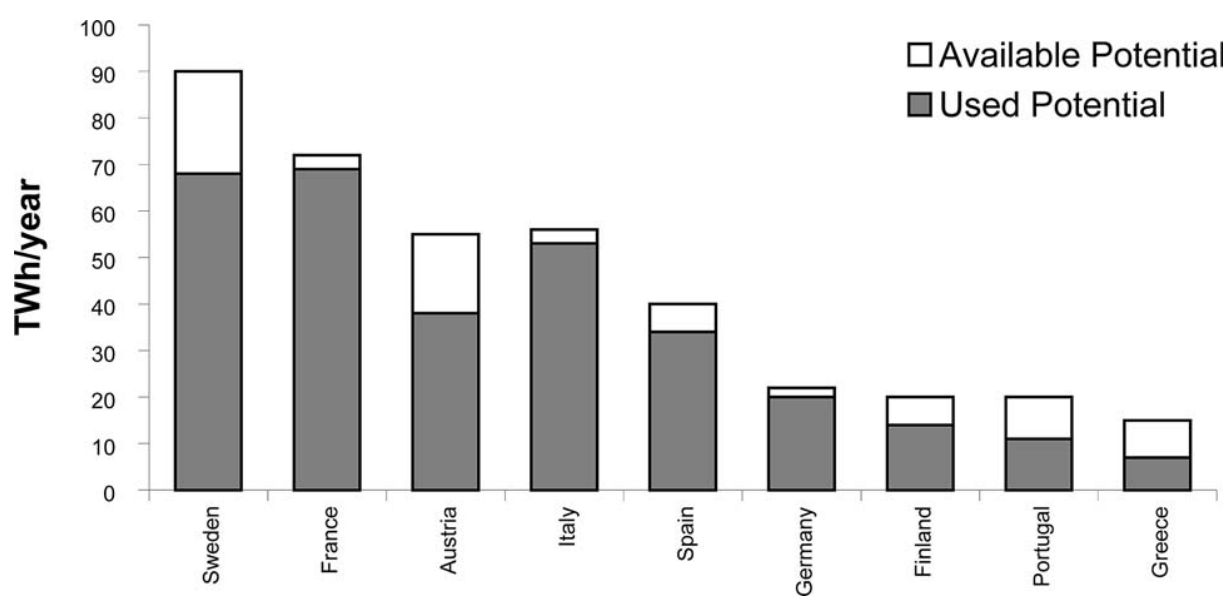

Fig. 1. Hydropower generation potential utilization in the European Union; Source: [10].

Beyond the electricity production, hydropower dams can provide structuring social and economic development. In Fig. $2^{1}$, we present the rainfall map of the Iberian Peninsula. With the exception of its Northern part, this area is characterized by very irregular rainfall patterns. The Southern part of the Peninsula is also semi-arid.

Unlike other renewable energy production processes, as wind power or solar energy, hydropower can provide multiple benefits that transcend the specific objective of the electrical energy production. This is a structuring investment with multiple impacts in the quality of life of the populations and in the economy (agriculture, forest and tourism), contributing to a balanced development of areas very featuring irregular rainfall patterns and scarcity of water.

In the Third World Water Forum (March of 2003) in Japan (Kyoto, Shiga and Osaka) [20], the Ministerial Conference culminated in the ratification of a formal Declaration, which includes specific reference to hydropower: (Item 15) "We recognize the role of hydropower as one of the renewable and clean energy sources, and that its potential should be realized in an environmentally sustainable and socially equitable manner."

Both the Kyoto Declaration and the Johannesburg Implementation Plan are fundamental mandates for the future role of hydropower. These statements support that:

(a) Hydropower is renewable and clean.

(b) Renewable energies policy/legislation should include hydropower of all scales.

(c) Attempts to define hydropower as an "old" or "new" renewable are irrelevant.

(d) Hydropower's implementation (including refurbishment/upgrading) should be increased.

\footnotetext{
${ }^{1}$ Humid Summer Limit—every mouths higher than $30 \mathrm{~mm}$.
} 


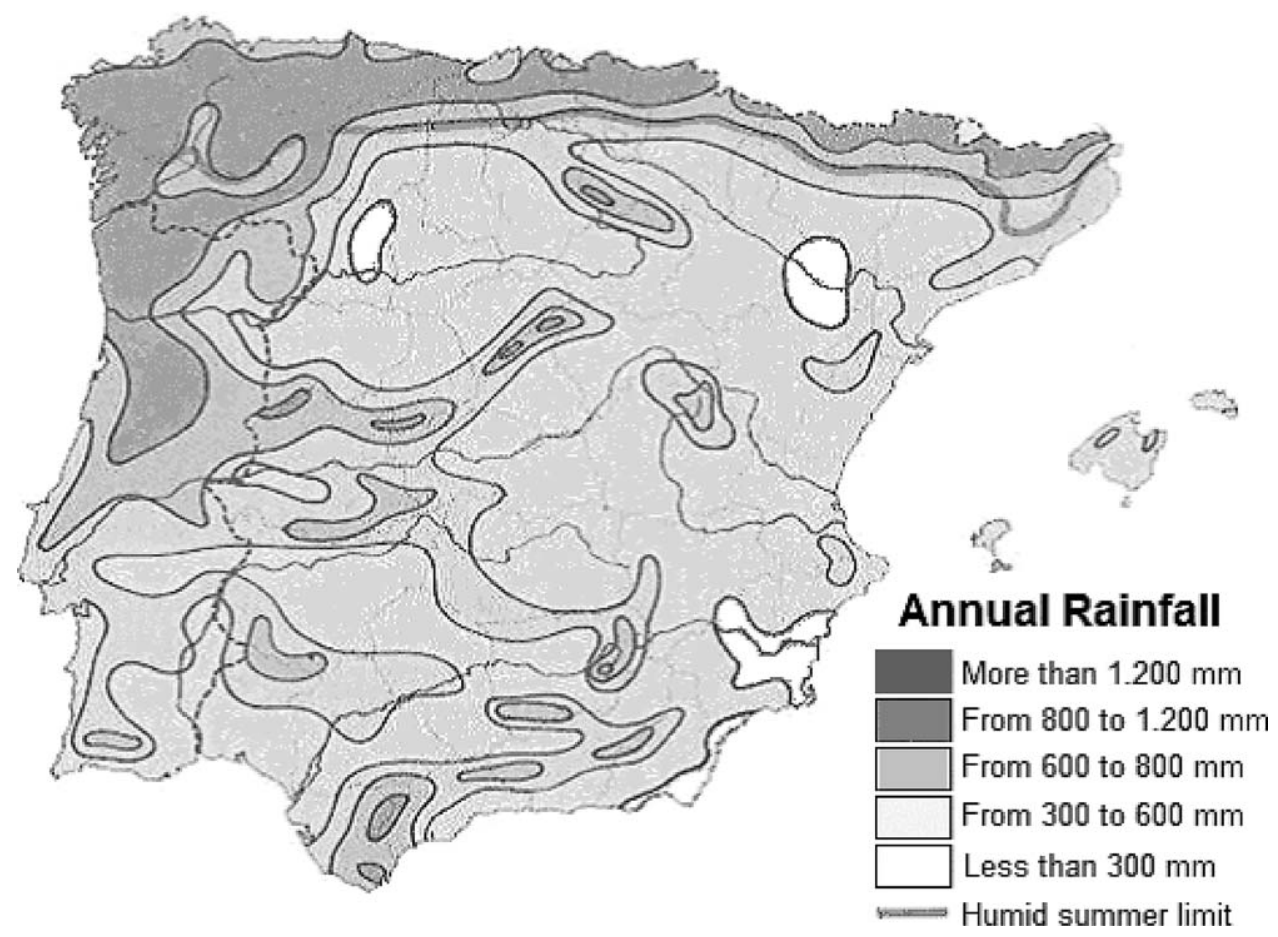

Fig. 2. Annual rainfall in the Iberian Peninsula.

(e) According to the circumstances, there is a role for both large and small schemes.

(f) Environmental awareness and sensitivity to locally affected people are key aspects.

(g) The sector must continue to evaluate and promote good practices.

Yet, likewise in all large projects, it will be also necessary to consider the negative impacts. The global merit of each project must inevitably be found by a balance between the benefits and the damages. In order to measure these impacts, a scale was established attributing 20 points to the most positive impact, 10 points to the null (net zero) impact and zero to the most negative impact. Once these impacts are measured, the ranking of each project can be computed using the following global impact function:

$$
r(x)=\sum_{i=1}^{5} w_{i} I_{i}(x)
$$

where $r(x)$ is the ranking for site $x, w_{i}$ is the weight of $i$ th impact factor and $I_{i}(x)$ is the impact of factor $i$ on site $x$. The first impact factor is the overall energy value, 
the second represents the value of the water resources aspects, the third stands for the social-economic development, the fourth is related to agricultural impact, and the fifth impact factor is related to the environment. The weights included in Eq. (1) were agreed by the decision panel of multi-disciplinary experts involved and consulted in the evaluation. Since the main reason for the investments is the production of electricity, the panel agreed that the energy impact factor should have a higher value, in the range from 0.5 to 0.8 , with the remaining weight distributed in a proportional manner by the other impact factors. Such agreement aims at satisfying the condition:

$$
\sum_{i=1}^{5} w_{i}=1
$$

On the other hand, the impact factor functions $I_{i}(x), i \in[1 ; 5]$ result from the aggregation previously described of sub-factors representing second level impact factors that can be grouped into the five major impacts above mentioned.

\section{Hydropower resources in Centre Region}

In 1993, the Centre Region Energy Plan identified 110 potential small hydropower plants and 14 medium and large hydropower plants planned by the electrical supply sector. Since 1993, a very small number of small hydropower plants were built. Those 14 new medium and large hydropower plants (Table 1) can produce $1775 \mathrm{GWh}$ in an average year [4].

The predicted climatic changes in Southern Europe, an in particular in Portugal, are an additional reason to build these dams, because they enable a safety increase in the water supply/irrigation and drought/flood control. The study from the Intergovernmental Panel on Climate Change (IPCC) [9], made with the United Nations support, predicted a decrease in the rainfall in Southern Europe and an increase in the irregularity of the precipitation regime (floods followed by severe droughts), during the XXI century.

The SIAM Project - climate change in Portugal [18], predicts the following impacts:

- Increase of the average monthly temperature between 3 and $5{ }^{\circ} \mathrm{C}$ in the Winter and $2{ }^{\circ} \mathrm{C}$ in the Summer months;

- Decrease of the average annual rainfall between $5 \%$ and $15 \%$ in the North of the country, decrease that can reach $30 \%$ in the south of the country;

- In the north and centre, increase of the monthly rainfall in the winter in $10 \%$ and a decrease in the other seasons. Between June and October, the decrease can reach $20 \%$ to $30 \%$;

- In the south, in the summer a decrease in the rainfall above $30 \%$ can occur;

- Increase of the spatial asymmetries; 
Table 1

Medium and large hydropower plants identified in Central Region of Portugal

\begin{tabular}{llrrrr}
\hline River & Dam & $\begin{array}{l}\text { Gross head } \\
(\mathrm{m})\end{array}$ & Flow $\left(\mathrm{m}^{3} / \mathrm{s}\right)$ & $\begin{array}{l}\text { Electric power } \\
(\mathrm{MW})\end{array}$ & $\begin{array}{l}\text { Annual energy } \\
\text { production } \\
(\mathrm{GWh})\end{array}$ \\
\hline Paiva & Portela & 93 & 25 & 19 & 35 \\
Paiva & Castro Daire & 234 & 51 & 100 & 162 \\
Paiva & Alvarenga & 120 & 100 & 102 & 194 \\
Paiva & Castelo de Paiva & 70 & 124 & 73 & 120 \\
Vouga & Póvoa & 178 & 32 & 44 & 65 \\
Vouga & Pinhosão & 114 & 47 & 45 & 66 \\
Vouga & Ribeiradio & 67 & 75 & 44 & 100 \\
Mondego & Asse-Dasse & 636 & 30 & 163 & 304 \\
Mondego & Girabolhos & 131 & 78 & 88 & 177 \\
Mondego & Midões & 63 & 90 & 54 & 99 \\
Côa & Atalaia & 123 & 48 & 45 & 66 \\
Côa & Sr. ${ }^{\text {a do Monforte }}$ & 145 & 65 & 78 & 113 \\
Côa & Pêro Martins & 150 & 100 & 126 & 181 \\
Ocreza & Alvito & 104 & 60 & 56 & 93 \\
Total & & & & 1037 & 1775 \\
\hline
\end{tabular}

- Increase of the seasonal asymmetries with a probable intensification of the extreme precipitation phenomena's;

- The number of days with a rainfall above $10 \mathrm{~mm}$ will be smaller.

\section{Energy impacts}

Hydropower has peculiar characteristics of primordial importance to the electric system, such as [11]:

- Hydropower dynamic characteristic enables a nearly immediate response to the load variations, and thus, a fast adjustment between the electric production and the demand. Its ability to go from zero power to maximum power output quickly and predictably is almost unique among generation sources. This characteristic is very important in the peak of the load diagram, contributing to a effective frequency regulation;

- By the same motive, hydropower allows an increase of the power system reliability, enabling a fast intervention in incident situations. This aspect has a vital importance due to the high financial losses associated with power interruption situations;

- The dams can storage high quantities of energy, which is the unique feasible way of creating operational reserves, rapidly available with high strategic value;

- In dams with pumped storage, it is possible to transfer energy produced in low cost hours to the peak periods, with an important economic benefit.

In 2003, the Portuguese Government set the goal of installing until 2010, 3750 MW of wind power $(35 \%$ of the actual total installed power), with the purpose of 
achieve a $39 \%$ renewable electricity production [3]. This strategy is risky because the high subsidies attributed to renewable generation can originate a high increase in the electricity costs. Additionally there are some reliability concerns, related to random power generation associated with wind power.

The large scale penetration of intermittent energy sources, like wind power or solar energy, must be compensated with power generation facilities that ensure the adjustment between the production and the electricity consumption. Hydropower schemes with storage capacity can provide cost-effective large scale integration of intermittent energy sources, without requiring expensive back-up thermal power plants. This is possible because of their extraordinary flexibility to satisfy the load diagram variations.

The energy impact of each dam was evaluated in a normal hydrological year, considering the economic benefit of the electricity production, through the addition of four items:

- Electric energy and power value - economic value of the contribution in normal operation regime, both of the energy and power, to the national electric grid (valued at $0.04 € / \mathrm{kWh}$ );

- Reserve capacity potential value - economic value associated to the utilization of this reserve in critical periods;

- Dynamic response value (load following capabilities) - economic value of a set of benefits associated with fast response of hydropower (replacing or decreasing the use of spinning reserve);

- Environmental premium-economic value of the carbon dioxide emissions reduction by avoiding the emissions of the thermal power plants to generate the same amount of energy.

For the reserve capacity potential evaluation of new dams, the Portuguese utility REN used two criterions [17]:

- Simulation of the hydrological regimes of 1957, 1976 and 1992 (dry years), releasing the reserve volume in the critical months. The hydropower production replaces the production of the simple cycle gas turbines;

- The increase of installed power in thermal equipment with characteristics of production in peak hours is replaced by the releasing of the reserve volume.

The application of these two criterions resulted in a valorisation between $20 \%$ and $50 \%$ of the electric value. Considering these results, the reserve capacity potential was evaluated as having an average value of $35 \%$ of the electric (energy and power) value. In the Alvarenga, Castelo de Paiva and Ribeiradio dams the reserve capacity potential was not considered because these dams are situated in the lower part of the rivers and they are projects principally destined to public water supply and to agriculture [15].

In 1996, the UNIPEDE (International Union of Producers and Distributors of Electrical Energy) has carried out an analysis about the dynamic response (load 
following) value [19]. The study analysed a hydropower park, constituted by power plants of various countries of the UCPTE (Union for Power Production and Transport Coordination), representing an installed total power of $100 \mathrm{GW}$. The conclusion of the study was that the additional value of the dynamic response relative to the programmed energy production is between 12\% (low capacity run of water dams) and 30\% (dams with large reservoirs). Considering that the hydro projects under consideration have large reservoirs in relation to the installed power, the dynamic response was valued as having $25 \%$ of the electric value.

For the environmental premium evaluation, the average $\mathrm{CO}_{2}$ specific emissions of the Portuguese thermal power plants $(622 \mathrm{~g} / \mathrm{kWh})$ was considered. The emissions reduction was valued in $25 € /$ ton $\mathrm{CO}_{2}$. This value was resulted of the average of the values (between 20 and $30 € /$ ton $\mathrm{CO}_{2}$ ) indicated in the preparatory work of the Portuguese Environment Council, of March of 1998, relative to the economic evaluation of the $\mathrm{CO}_{2}$ emissions. This value is also in line with the results of the European Climate Change Programme [6].

Applying these values, the evaluation of the hydropower production due to the emissions absence is $0.0155 € / \mathrm{kWh}$. It must be emphasized that the premium attributed by most European countries to renewable energies such as wind power is much higher than this value $(0.03-0.04 € / \mathrm{kWh})$.

Adding the four values associated with the different benefits, the total energy value for each dam is obtained. In a baseline scenario, the multi-purpose uses (other than energy) are responsible for an average of $30 \%$ of the investment, while the energy side is responsible for the remaining $70 \%$. The economic return (net present value) of each dam, that defines the energy ranking, was calculated with a conservative discount rate of $6 \%$ (Table 2).

Fig. 3 shows the energy ranking of the projects, in a scale of $0-20$. In this scale, 10 means zero NPV and 20 represents the maximum NPV. Two of the projects show slightly negative NPV values.

\section{Water resources impacts}

The construction of a dam can cause a significant impact in the water supply system, in the drought/flood control and in the strategic water reserves [7].

Several sub-regional water supply systems are planned in the Central Region of Portugal [8]. The year of 2006 is the dead-line date for conclusion of these water supply systems [13]. The ranking considering the water supply impact took into account the design/construction period of each dam, the storage capacity, the distance from the dams to the main consumption centres and the hydraulic head from the reservoir to the main consumption centres.

The ranking of the strategic water reserves was determined in function of the useful capacity of the dam reservoir.

The dams can contribute to mitigate the impacts of climate change, since they provide strategic water reserves to ensure irrigation, water supply and minimal ecological flows during the dry seasons. In the wet seasons then dams' action is also 
Table 2

Evaluation of the several energy impacts (in $10^{6} €$ )

\begin{tabular}{lccccrr}
\hline Dam & $\begin{array}{l}\text { Energy/ } \\
\text { power }\end{array}$ & $\begin{array}{l}\text { Reserve } \\
\text { capacity }\end{array}$ & $\begin{array}{l}\text { Dynamic } \\
\text { response }\end{array}$ & $\begin{array}{l}\text { Environmental } \\
\text { premium }\end{array}$ & Total & NPV \\
\hline Portela & 1.400 & 0.490 & 0.350 & 0.543 & 2.783 & -1.143 \\
Castro Daire & 6.480 & 2.268 & 1.620 & 2.512 & 12.879 & 101.874 \\
Alvarenga & 7.760 & 0.000 & 1.940 & 3.007 & 12.707 & 112.945 \\
Castelo de Paiva & 4.800 & 0.000 & 1.200 & 1.860 & 7.860 & 36.621 \\
Póvoa & 2.600 & 0.910 & 0.650 & 1.008 & 5.168 & 36.449 \\
Pinhosão & 2.640 & 0.924 & 0.660 & 1.023 & 5.247 & 27.702 \\
Ribeiradio & 4.000 & 0.000 & 1.000 & 1.550 & 6.550 & 57.265 \\
Asse-Dasse & 12.160 & 4.256 & 3.040 & 4.712 & 24.168 & 150.973 \\
Girabolhos & 7.080 & 2.478 & 1.770 & 2.744 & 14.072 & 97.968 \\
Midões & 3.960 & 1.386 & 0.990 & 1.535 & 7.871 & 44.452 \\
Atalaia & 2.640 & 0.924 & 0.660 & 1.023 & 5.247 & -17.298 \\
Sr. ${ }^{a}$ de Monforte & 4.520 & 1.582 & 1.130 & 1.752 & 8.984 & 25.143 \\
Pêro Martins & 7.240 & 2.534 & 1.810 & 2.806 & 14.390 & 59.126 \\
Alvito & 3.720 & 1.302 & 0.930 & 1.442 & 7.394 & 26.910 \\
Total & 71.000 & 19.054 & 17.750 & 27.517 & 135.321 & 777.428 \\
\hline
\end{tabular}

fundamental to ensure flood control if the reservoir storage capacity is considerable.

In order to evaluate the flood control ranking, the flood retention capacity of each dam was compared with the millenarian flood volume in two different river sections: nearby the dam and down-stream the dams in the beginning of the flooded areas.

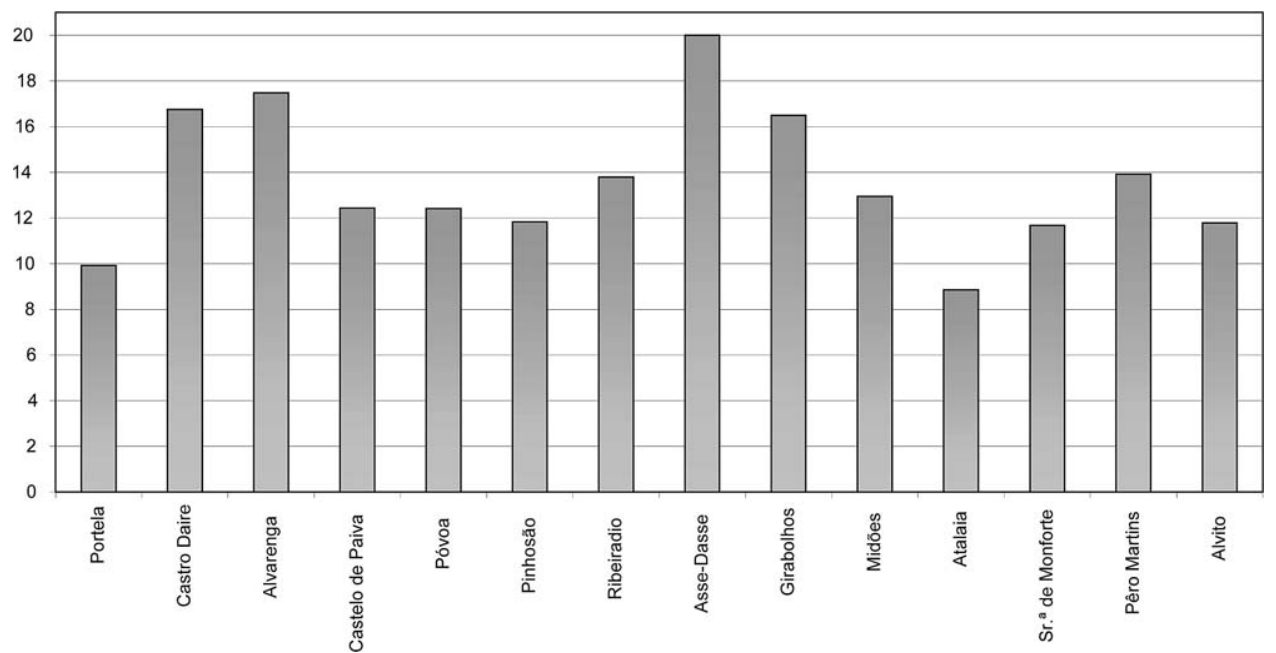

Fig. 3. Energy impacts ranking. 


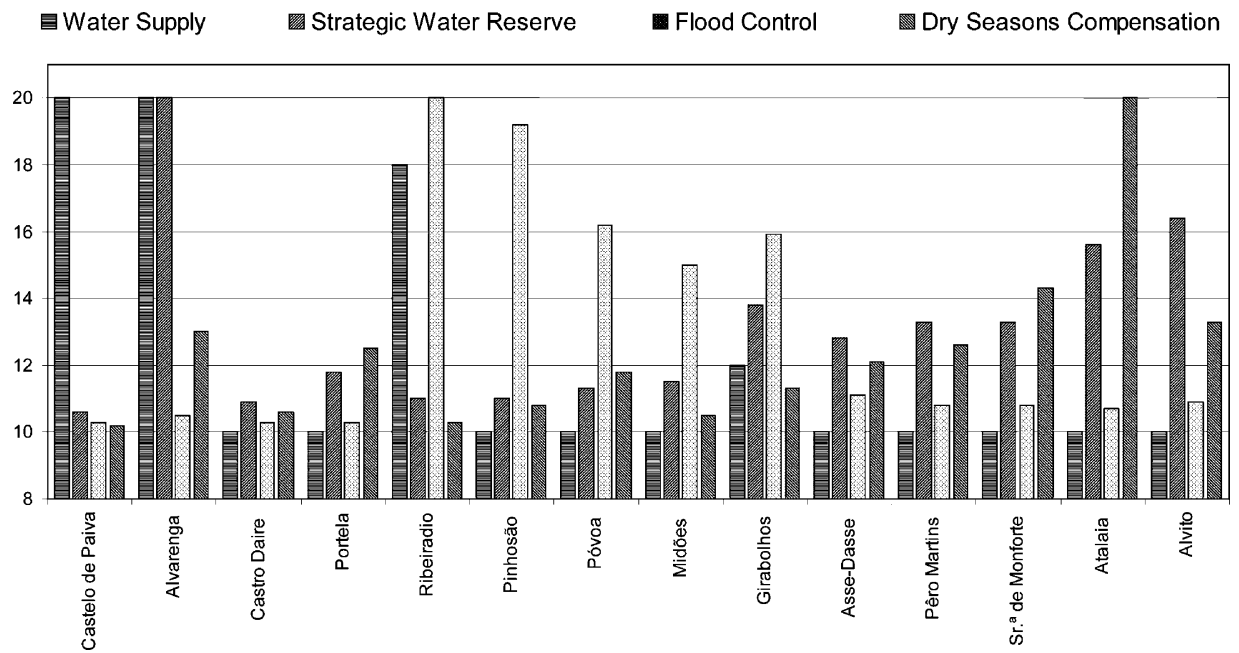

Fig. 4. Water resources rankings.

In order to evaluate the drought compensation, the capacity of the dam reservoirs was compared with the corresponding annual inflow in dry years. The storage capacity of each dam reservoir was also compared with the difference of inflow between a dry year and a normal hydrological year. Fig. 4 shows the water resources rankings.

\section{Social-economics development impacts}

In addition to the direct impacts, the dams construction induce effects in the local economies due to new conditions that enable the development of different economic activities. The existence of a dam is an important resource to the creation of new activities associated to sport, tourism and leisure, promoting the diversification of the economy and an increase of the employment in the surrounding territories.

In terms of leisure activities, the main distinction between the different dams, is in the capability to attract consumers. To define the ranking, a gravitational attraction model was used that distinguishes the dams as a function of the resident population in the surrounding places with a pondering factor: the time needed to come from any place to the dam. The model allows the construction of the Economic Attraction Index (EAI) that establishes the first evaluation of the dams.

However this index, does not consider other economic effects, namely the agricultural impact. In this sector, the impacts were availed as a function of the productivity increase in the dams down-stream grounds, benefiting from the flood control and water availability during dry periods. The conjunction of these two 


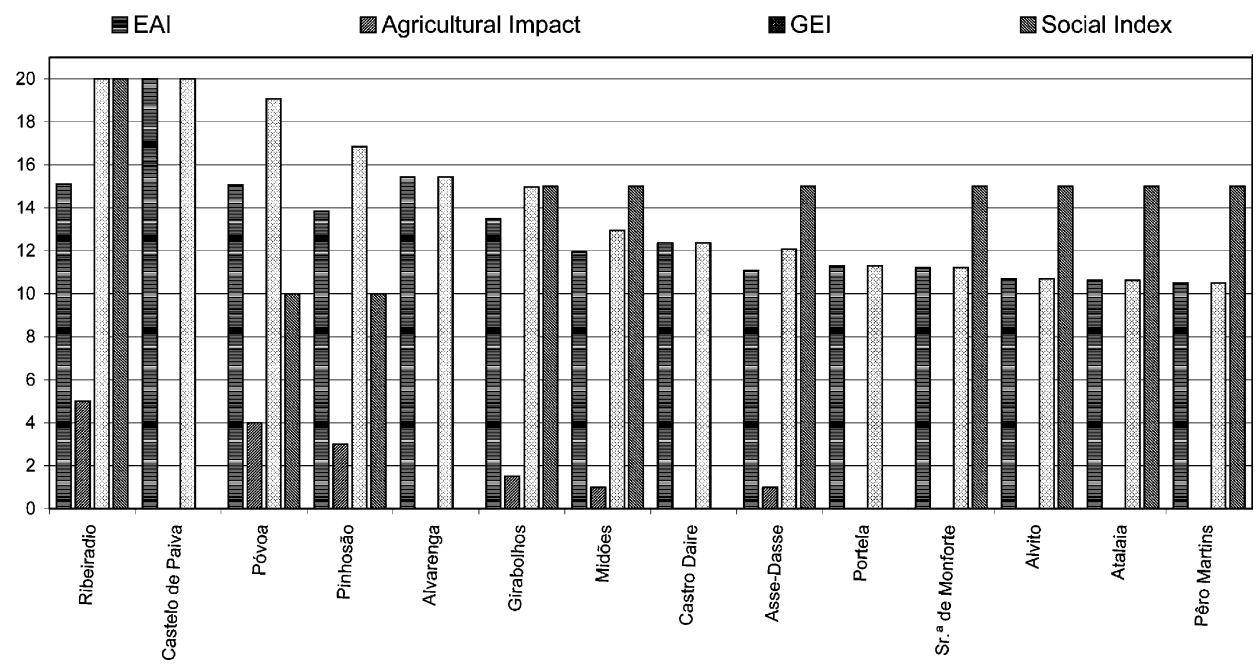

Fig. 5. Social-economics development rankings.

factors enables the construction of a Global Economical Index (GEI) that established the ranking of the economical impact.

A dam construction and the consequent lagoon formation, have inevitable impacts on the population's life. However, it is difficult to interrogate directly the populations. To evaluate the social impacts and the local acceptance, all the elected Mayors of the counties involved in the future hydropower plants, were requested to rate the impact on their council. The Mayors' ratings established the social index, defined between 0 and 20, in which 0 is the total opposition to the project and 20 the convict support.

Fig. 5 shows the social-economics rankings.

\section{Animal and plant life environmental impacts}

A dam produces impacts on the river ecosystems that affect the fauna and the flora in the river region.

In the dam area, the following impacts can occur: loss of habitats and biodiversity; loss of aquatic vegetation; decrease of water quality; loss of fish communities; alteration of the landscape; accumulation of sediments in the reservoir and organic material accumulation.

In down-river and up-river areas, the following impacts can occur: habitat fragmentation; decrease of water quality; obstruction of the fishes migratory movements; organic material transport; sediments transport; seasonal fluctuations of the water column and daily fluctuations of the water column [1].

For the present ranking, the dams were classified from 0 (more harmful to the environment) to 10 (minimal damage to the environment), considering the following criteria: 
- Classified areas inundated by the dam (natural parks, classified green areas, network zones and others);

- Percentage of classified areas inundated by the dam;

- Presence of marginal vegetation with ecological interest. The interest can result from the biodiversity, as an area of ecological protection or as a buffer-stopper in the pollution interception;

- Presence of down-river classified zones, because the flow regulation has ecological impacts in the aquatic ecosystems and marginal flora in the entire down-river areas;

- Affected habitats and/or species in the classified zones. This criterion is connected with the presence of unique species and theirs habitats. The species and habitats protected by European Commission legislation were considered;

- Inundated forest and brushwood areas;

- Conservation state of the fauna, considering the presence of native or intruder species;

- Other ecological indicators. In this case, the $k / T$ (elaborated within the compass of the Portuguese Plan of the Water [12]) index was adopted, that integrates the condition of the riverside vegetation, the fishes community, the biological and the chemical quality of the water.

The pondering sum of the above mentioned partial impacts determined the environmental impacts ranking (Table 3).

Although all projects show a global negative impact on the ecosystems, there are strong variations in magnitude of the impacts (Fig. 6).

\section{Improvement of forest fire combat capabilities}

The centre region in Portugal presents vast forest areas highly vulnerable to the devastation by summer fires. In 2003, catastrophic forest fires destroyed over 400,000 hectares of forest in Portugal. The availability of water was a critical constraint in these tragic events. An increase in the forest fires protection capabilities can be provided by the dam reservoirs due to:

- Local increase of the air humidity nearby the reservoir;

- Availability of water surfaces with sufficiently long landing surfaces to allow aerial fire combat.

A minimum length of the water surface of about $2 \mathrm{~km}$ is needed to make possible the use of fire combat airplanes. It is estimated that a significant reduction of the burned area is expected inside a $25 \mathrm{~km}$ radius centred in the water surface. Taking in to account these geometrical conditions, we computed the area with improved aerial fire combat conditions associated to each dam (Fig. 7). Fig. 8 shows the forest fire ranking based on the forest areas which can dealt with each reservoir. 


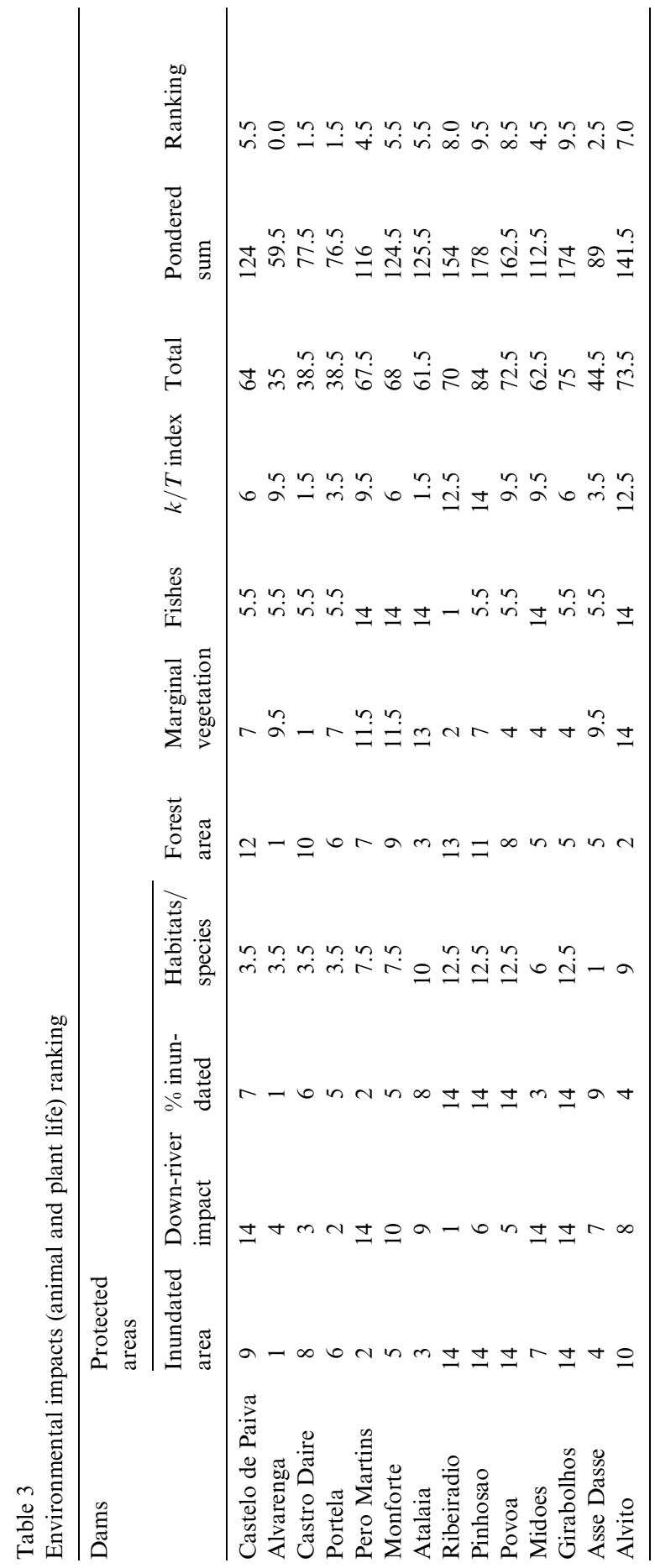




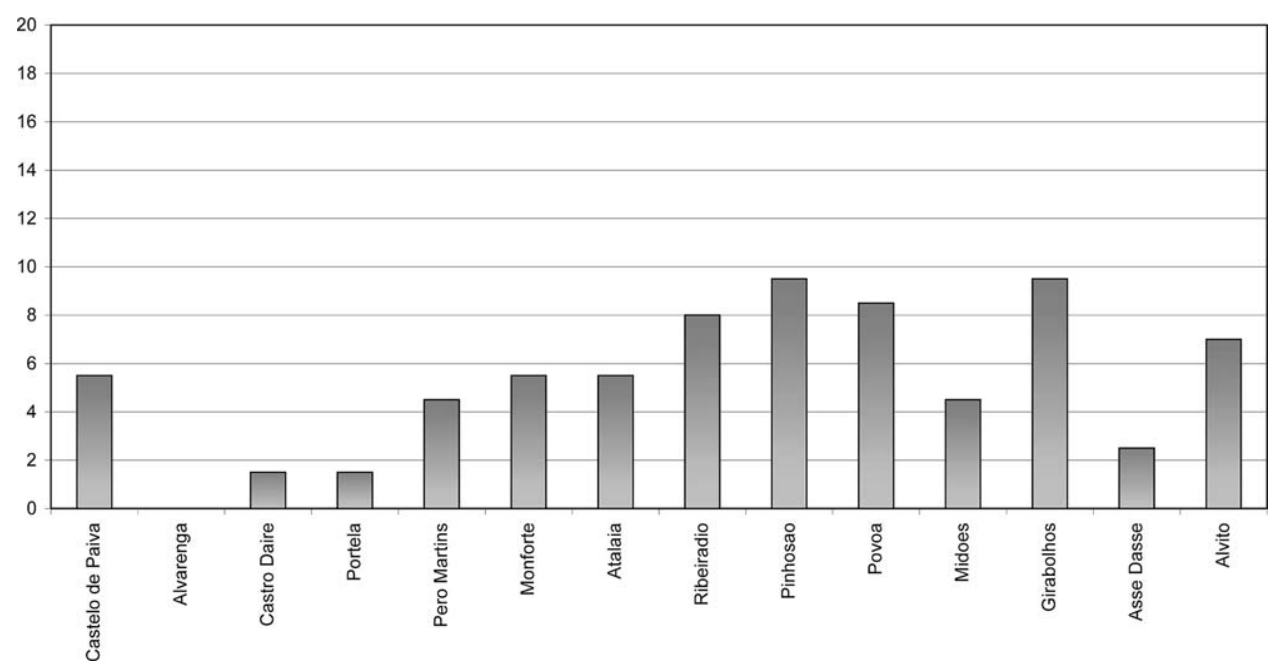

Fig. 6. Environmental impacts (animal and plant life) ranking 0-maximum impact, 10 - null impact.

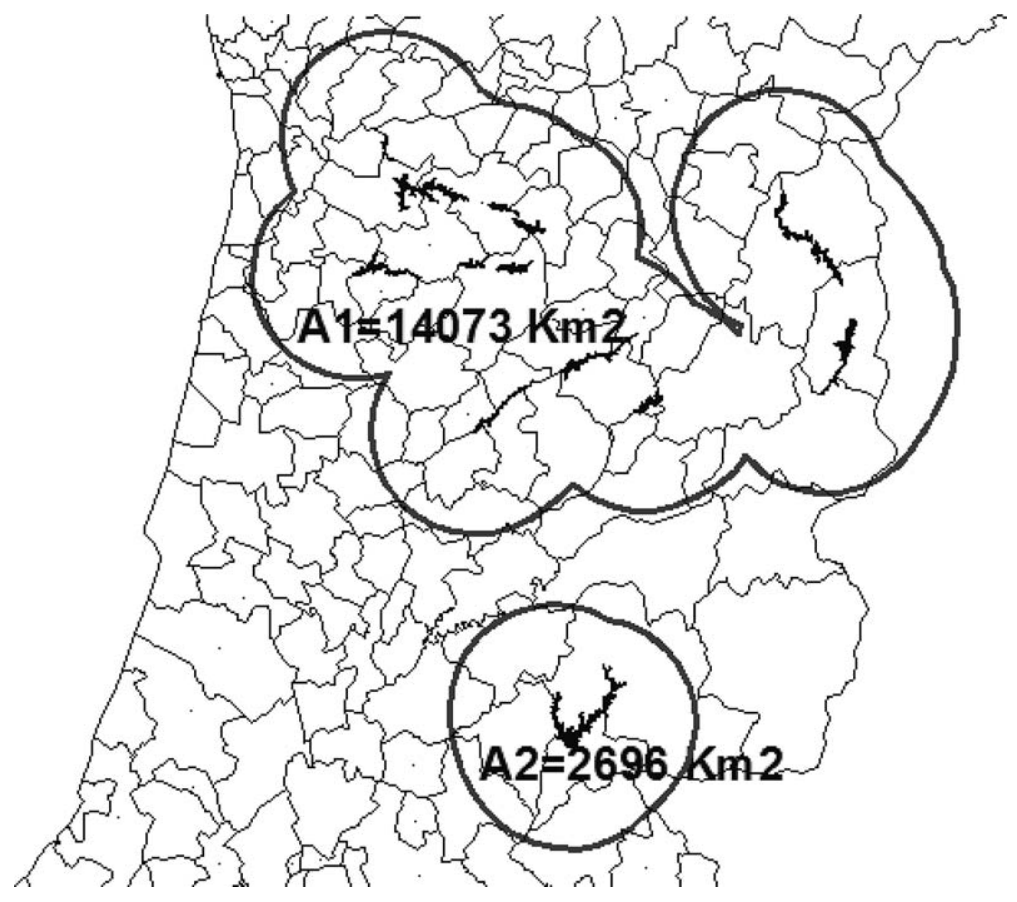

Fig. 7. Improved aerial forest fire combat areas. 


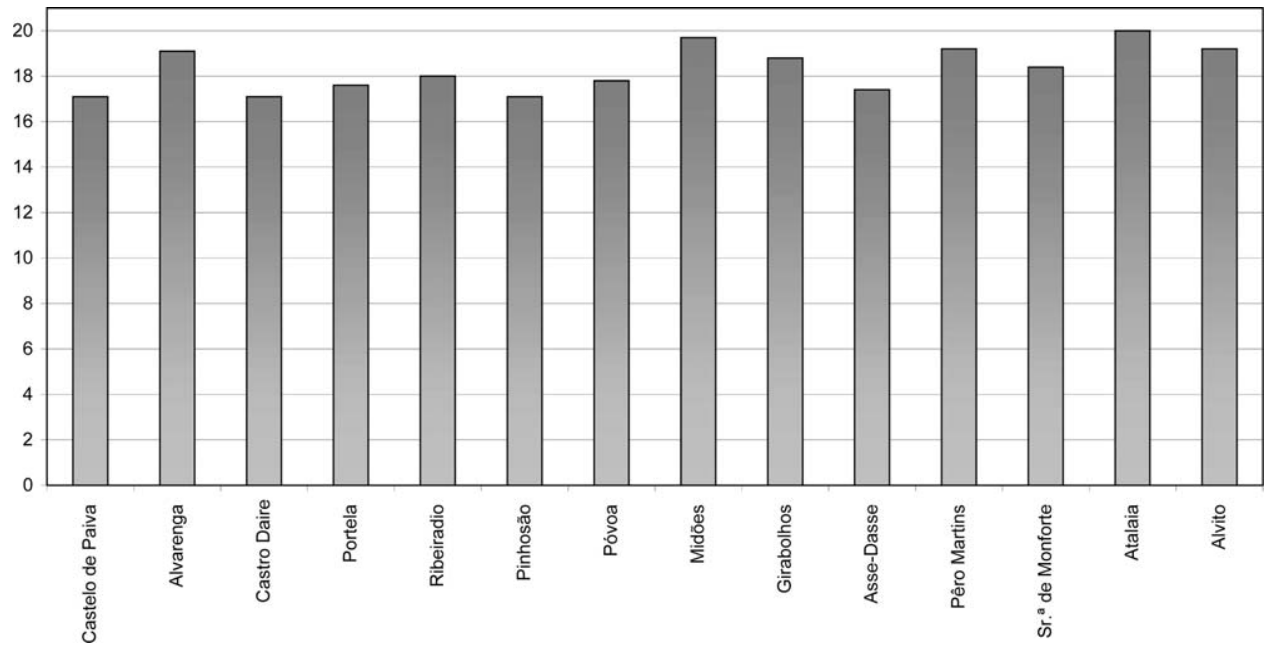

Fig. 8. Aerial forest fire combat improvement ranking.

\section{Global ranking}

In order to evaluate the global ranking, the impacts were grouped in the following categories:

- Energy (energy/power value, reserve capacity potential value, dynamic response value and emissions reduction value);

- Water reserve and supply (sub-regional water supply systems value and strategic water reserve value);

- Economics (economic attraction index and agriculture impact);

- Environment (improvement of forest fire combat capabilities, ecosystems impactanimal and plant life, flood control and capability of regularization in dry years);

- Social acceptance.

As the base scenery (Table 4), the energy value represents $70 \%$ of the impacts and the multiple impacts the remaining 30\%. To estimate the multiple impacts component, the following percentages were considered:

- $60 \%$ to the environmental impacts (50\% for the animal and plant life, $30 \%$ for the forest fire combat contribution, $10 \%$ for the capability of regularization in dry years and $10 \%$ for the flood control);

- $30 \%$ for the global economic index (economic attraction index and agricultural impact);

- $10 \%$ for the water reserve and supply capacity.

The social index that provides the populations acceptance was incorporated in the global evaluation pondering the multiple impacts with the following values:

- Index 20 -increase the multiple impacts by $20 \%$; 
Table 4

Global ranking

\begin{tabular}{ll}
\hline Dam & Ranking \\
\hline Asse-Dasse & 17.3 \\
Girabolhos & 16.1 \\
Ribeiradio & 16.0 \\
Pêro Martins & 13.2 \\
Midões & 12.9 \\
Póvoa & 12.9 \\
Pinhosão & 12.8 \\
Atalaia & 12.5 \\
Alvito & 12.1 \\
Sr. ${ }^{2}$ de Monforte & 11.9 \\
Alvarenga & 10.4 \\
Castro Daire & 8.7 \\
Castelo de Paiva & 5.6 \\
Portela & 4.4 \\
\hline
\end{tabular}

- Index 15 -increase the multiple impacts by $15 \%$;

- Index 10 - the multiple impacts stay unaltered.

In the case of the dams rejected by the populations, the multiple benefits are considered negatives.

To analyze the results consistence, a sensitivity analysis was carried out, changing the energy component percentage between $50 \%$ and $80 \%$. The sensitivity analysis was performed by changing the weight of the energy impact $w_{1}$ in the interval $[0.5 ; 0.8]$ into discrete steps of 0.1 . Every change of $w_{1}$, leads to a proportional decrease of the other weights and the changes are reflected in the ranking value (cf. Eq. (1)). The results of the sensitivity analysis are represented in Fig. 9.

The sensitivity analysis shows that the ranking variations are only slightly influenced by the changes in energy component weight. In terms of overall ranking, the dams can be divided in three categories:

- Asse-Dasse, Girabolhos and Ribeiradio;

- Pêro Martins, Póvoa, Midões, Pinhosão, Alvito, Sr. ${ }^{a}$ de Monforte and Atalaia;

- Castro Daire, Castelo de Paiva and Portela.

For the three first hydropower plants, the corresponding multi-impact net diagram is presented in Fig. 10.

\section{Conclusions}

Recently the medium and large hydropower plants have faced strong resistance. This opposition results in large part from the environmental impacts on the river ecosystems produced by the dam. Although it is true that a large dam affects the fauna and the flora in the river region, the hydropower dam can also bring many 


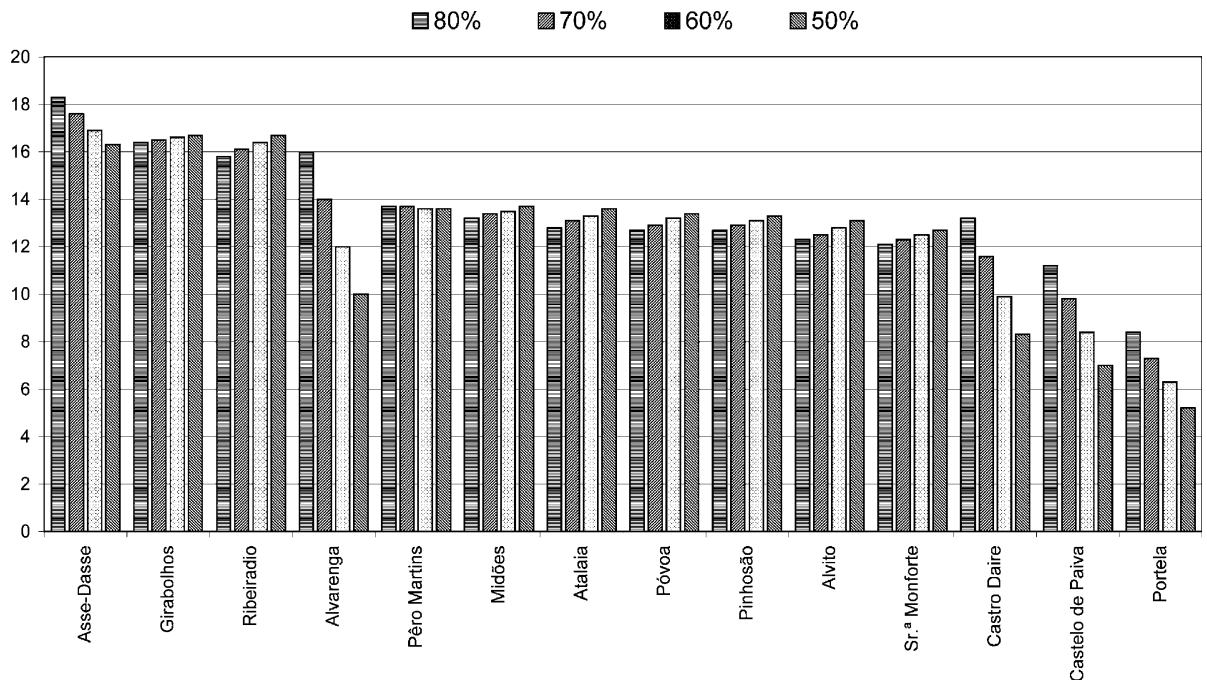

Fig. 9. Sensitivity analysis.

advantages to the environment, particularly in areas with very irregular water flow and in areas with potential shortage of water. Other environmental benefits of the hydropower plants include the improvement of forest fires combat support. The hydropower can also provide multiple benefits that transcend the specific objective
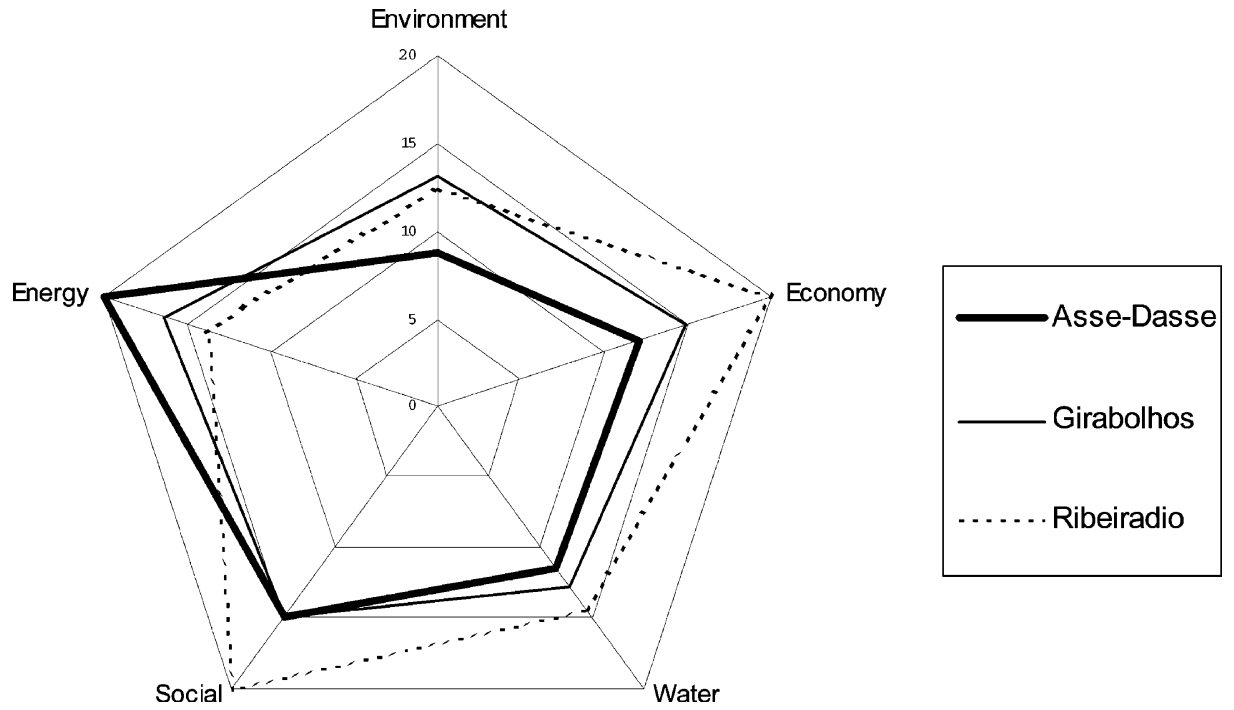

Fig. 10. Multi-impact net diagram. 
of the electrical energy production, being a key factor to the regional development, supporting improved water supply, irrigation and tourism.

In Portugal, hydropower will help in a significant way to meet the Kyoto objectives of carbon dioxide emissions reduction. The hydropower schemes with storage capacity can also provide cost-effective large scale integration of intermittent energy sources (such as wind and solar power), without requiring expensive backup thermal power plants.

Fourteen projects were analyzed, considering the different positive and negative impacts. The adopted methodology enables the integration of the various impacts, allowing the establishment of a ranking of priorities in the construction of the dams. Local elected representatives were involved in the ranking process and this provides a higher degree of confidence and legitimacy in the decision process.

\section{References}

[1] Bergkamp G, McCartney M, Dugan P, McNeely J, e Acreman M. Ecosystem functions and environmental restoration. 2000.

[2] CCRC - Comissão de Coordenação da Região Centro, Coimbra, Portugal, HidroValor projectevaluation of economical, social and environmental impacts of new medium and large hydropower plants in Portugal Centre Region (in Portuguese), Universidade de Coimbra; 2003.

[3] DGA, Direcção Geral do Ambiente, Portugal, National Programme to the Climate Changes (in Portuguese), CEEETA, UNL/DCEA, CESUR; 2002.

[4] EDP, Electricidade de Portugal S.A.. Hydropower resources inventory (in Portuguese). Direcção Operacional do Equipamento Hidráulico; 1988.

[5] ERSE, Entidade Reguladora dos Serviços Energéticos, Characterization of the Electrical Sector2001 (in Portuguese); 2002.

[6] EU, Commission of the European Communities, European Climate Change Programme (ECCP); 2001.

[7] HIDRORUMO. Preliminary evaluation of the flood control in the Dam of Baixo Sabor (in Portuguese). 2001.

[8] INAG, FCUL. Characterization of the Portuguese aquifer's systems (in Portuguese). 1998.

[9] Intergovernmental Panel on Climate Change. Climate Change 2001: impacts, adaptation, and vulnerability, summary for policymakers and technical summary of the working group II report; 2001.

[10] Leitão Rui. The hydropower situation in Portugal and in the European Union (in Portuguese). 2000.

[11] National Hydropower Association. Averting disaster: keeping the lights on with hydropower. 2002.

[12] Portugal, Ministério do Ambiente e do Ordenamento do Território. National plan of the water (in Portuguese). Instituto da Água; 2000.

[13] Portugal, Ministério do Ambiente e do Ordenamento do Território. Strategic plan of water supply and sanitation of residual waters (2000-2006) (in Portuguese). 2000.

[14] Portugal, Ministério da Economia. Expansion plan of the electrical system (in Portuguese). 1999.

[15] REN, Rede Eléctrica Nacional, Multipurpose Dams of the Paiva River (in Portuguese), Direcção de Planeamento do Sistema Produtor; 2000.

[16] REN, Rede Eléctrica Nacional, Hydropower in Portugal-memory and challenge (in Portuguese), Carlos Madureira e Victor Baptista; 2002.

[17] REN, Rede Eléctrica Nacional. Economical analysis of the Dams of Baixo Sabor and Alto Côa (in Portuguese). 2002.

[18] Santos F, Forbes K, Moita R. Climate change in Portugal—scenarios, impacts, and adaptation measures. 2001. 
[19] UNIPEDE, Quantification and evaluation of hydroelectric energy in the european generation mix, Hydro-Power and Other Renewable Energies Study Committee; 1996.

[20] WWF, Secretariat of the 3rd World Water Forum, The 3rd World Water Forum-final report; 2003. 